ISSN 2073-4344

www.mdpi.com/journal/catalysts

Review

\title{
Acyclic Diene Metathesis (ADMET) Polymerization for Precise Synthesis of Defect-Free Conjugated Polymers with Well-Defined Chain Ends
}

\author{
Tahmina Haque ${ }^{1,2}$ and Kotohiro Nomura ${ }^{1,3, *}$
}

1 Department of Chemistry, Tokyo Metropolitan University, 1-1 Minami Osawa, Hachioji, Tokyo 192-0397, Japan; E-Mail: tahmina_haque75@yahoo.com

2 Department of Chemistry, Jahangirnagar University, Savar, Dhaka 1342, Bangladesh

3 Advanced Catalytic Transformation for Carbon Utilization (ACT-C), Japan Science and Technology Agency (JST), Saitama 332-0012, Japan

* Author to whom correspondence should be addressed; E-Mail: ktnomura@tmu.ac.jp; Tel./Fax: +81-42-677-2547.

Academic Editor: Keith Hohn

Received: 1 December 2014 / Accepted: 9 March 2015 / Published: 30 March 2015

\begin{abstract}
This accounts introduces unique characteristics by adopting the acyclic diene metathesis (ADMET) polymerization for synthesis of conjugated polymers, poly(arylene vinylene)s, known as promising molecular electronics. The method is more suitable than the other methods in terms of atom efficiency affording defect-free, stereo-regular (exclusive trans) polymers with well-defined chain ends; the resultant polymers possess better property than those prepared by the conventional methods. The chain ends (vinyl group) in the resultant polymer prepared by ruthenium-carbene catalyst(s) can be modified by treating with molybdenum-alkylidene complex (olefin metathesis) followed by addition of various aldehyde (Wittig type cleavage), affording the end-functionalized polymers exclusively. An introduction of initiating fragment, the other conjugated segment, and one-pot synthesis of end-functionalized block copolymers, star shape polymers can be achieved by adopting this methodology.
\end{abstract}

Keywords: conjugated polymers; metathesis; ruthenium; molybdenum; defect-free; PFV 


\section{Introduction}

Organic electronics are important emerging technologies, and conjugated polymers like poly(p-arylene vinylene)s are promising materials as novel class of organic semiconductors [1-4]. It has been known that the properties for their device efficiency are generally influenced by their structural regularity, chemical purity, and supramolecular order [1-4]. Both high temperatures $\left(180-300{ }^{\circ} \mathrm{C}\right)$ and vacuum conditions are employed to convert nonconjugated precursor polymers into poly ( $p$-phenylene vinylene)s (PPVs, Scheme 1(1)) [1,5,6]; the synthetic procedure is very sensitive to trace amounts of oxygen during the conversion step that generates oxidation products $[5,6]$. These structural defects reduce the luminescence quantum efficiency of the final PPV films. There are still several concerns, such as impurities (halogen, sulfur, etc.) and structural (stereo-, regio-) irregularity in other conventional methods (shown in Scheme 1 such as (3) Horner-Wittig-Emmons (HWE) reactions or (4) Heck coupling, etc.) [1-6]. Therefore, considerable attention has thus been paid to a study for synthesis of structurally regular, chemically pure polymers by development of new synthetic methods.
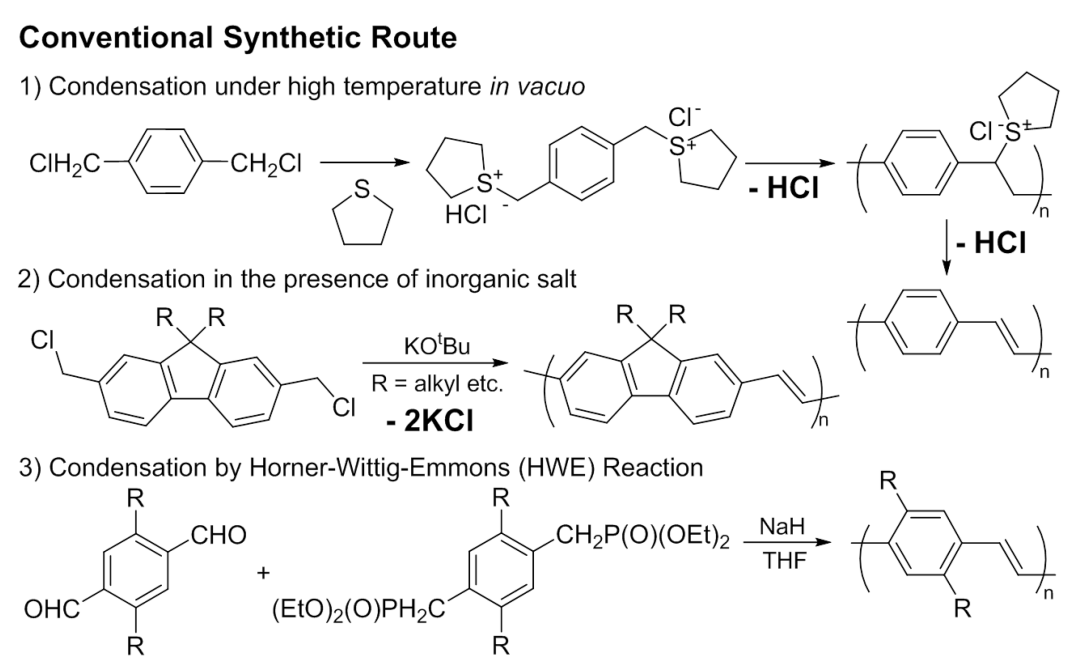

4) Condensation by Heck Reaction

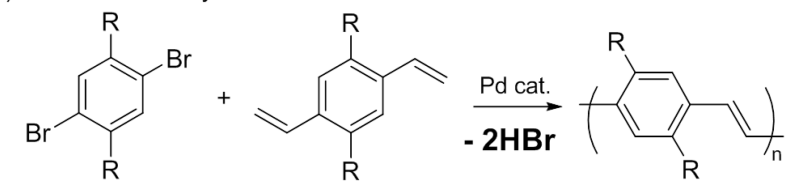

Scheme 1. Conventional routes for synthesis of poly(arylene vinylene)s [1-6].

Recently, it has been demonstrated that acyclic diene metathesis (ADMET) polymerization [7-11] offers a new possibility as the efficient route of $\pi$-conjugated materials [12-24]. We first demonstrated a synthesis of high molecular weight, all trans poly(9,9-di-n-octyl-fluorene-2,7-vinylene) (PFV) by ADMET polymerization of 2,7-divinyl-9,9-di- $n$-octyl-fluorene using Schrock type molybdenum-alkylidene [21]. $\mathrm{Ru}(\mathrm{CHPh})(\mathrm{Cl})_{2}\left(\mathrm{IMesH}_{2}\right)(\mathrm{PCy} 3) \quad\left(\mathrm{Cy}=\right.$ cyclohexyl, $\mathrm{IMesH}_{2}=$ 1,3-bis(2,4,6-trimethylphenyl)-2imidazolidinylidene), was also effective for syntheses of high molecular weight poly(2,5-dialkylphenylene-1,4-vinylene)s (PPVs) [22], PFVs and poly( $N$-alkylcarbazole-2,7-vinylene)s (PCVs) [23] (Scheme 2). The fact introduced an interesting contrast, because the initial attempts by this approach afforded oligomer mixtures [12-20]. It turned out that an optimization of the reaction conditions (catalyst, monomer/catalyst molar ratios, initial monomer concentration, etc.), especially removal of 
ethylene by-produced from the reaction medium should be prerequisite for obtainment of the high molecular weight polymers in this condensation polymerization [21-23].

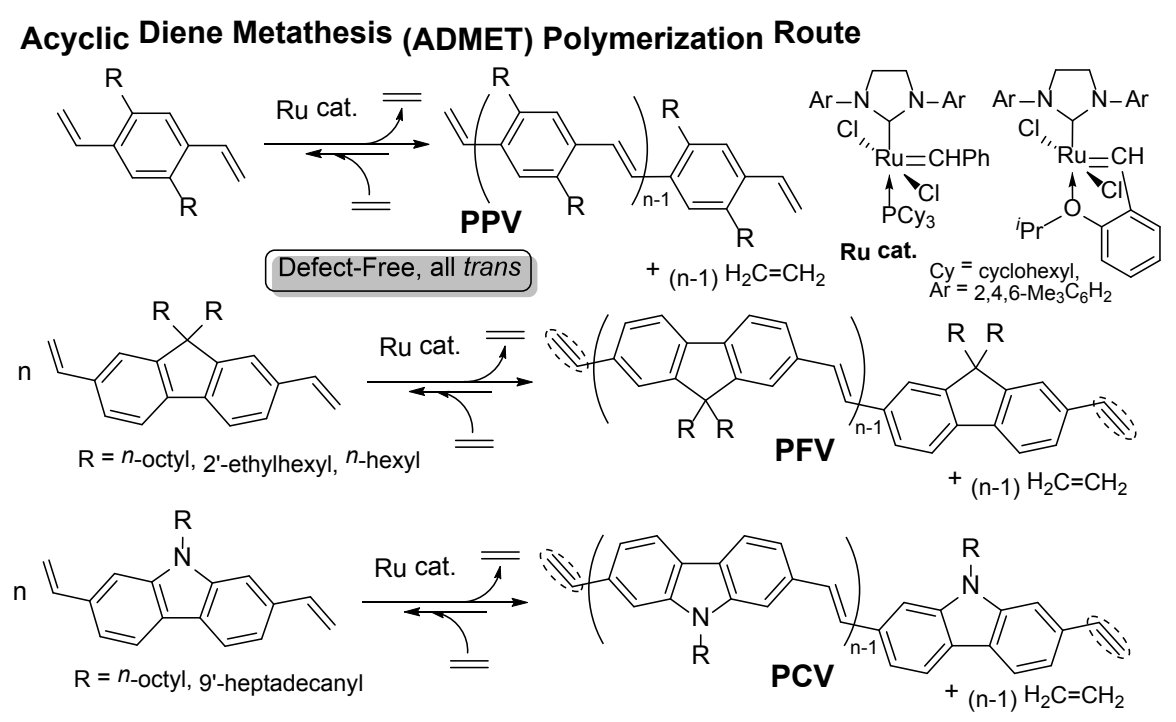

Scheme 2. Acyclic diene metathesis (ADMET) (right) [21-23] routes for synthesis of poly(arylene vinylene)s.

The promising characteristics by adopting this approach can be summarized as follows: (1) the resultant polymers are defect-free (without termination of the conjugated units, without containing any negative impurities such as halogen, sulfur), (2) the resultant polymers (oligomers) possessed highly trans olefinic double bonds (because, as initially proposed by Thorn-Csányi et al. [7,8,11-14], the reaction proceeds via metallacycle intermediate, Scheme 3). Moreover, the resultant polymers prepared by $\mathrm{Ru}$ catalyst possessed well-defined polymer chain ends (as vinyl group) [22,25-30]; therefore, modification of the conjugated materials can be demonstrated by utilization of the chain ends [25-30].

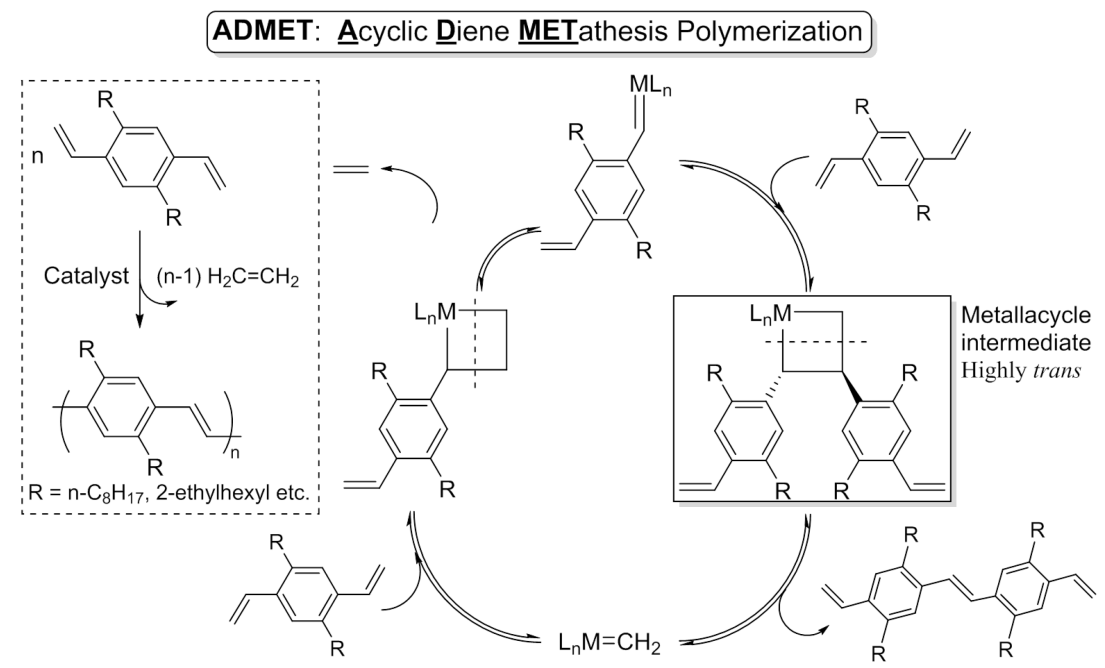

Scheme 3. Proposed mechanism for ADMET polymerization of 2,5-dialkyl-1,4divinylbenzene $[7,8,11-14,21-23]$. 
In this accounts, unique characteristics by adopting the ADMET polymerization methods in terms of properties in the resultant polymers as well as synthesis of various advanced materials especially by the end modifications, including the points that have to be taken into consideration for the efficient synthesis, have been introduced.

\section{Synthesis of Conjugated Polymers by ADMET Polymerization}

Table 1 summarizes the results for ADMET polymerization of 2,7-divinyl-9,9-dialkylfluorenes by ruthenium-carbene catalysts (Scheme 4). Synthesis of high molecular weight PFVs with uniform molecular weight distributions could be achieved by adopting this method under optimization of the reaction conditions (catalyst, monomer/catalyst molar ratios, initial monomer concentration, etc.), although the perfect control of the repeating units cannot be obtained in this condensation (step growth) polymerization $\left(M_{\mathrm{w}} / M_{\mathrm{n}}=c a .2\right)$. Continuous removal of ethylene by-product from the reaction medium should be prerequisite for obtainment of the high molecular weight polymers in the present polymerization due to an equilibrium shown in Scheme 3 [21-23]. The resultant polymers possess all-trans internal olefinic double bonds with defect-free nature (without termination of conjugation).

Table 1. Acyclic diene metathesis (ADMET) polymerization of 2,7-divinyl-9,9dialkylfluorene using various Ru-carbene complex catalysts [23] ${ }^{a}$.

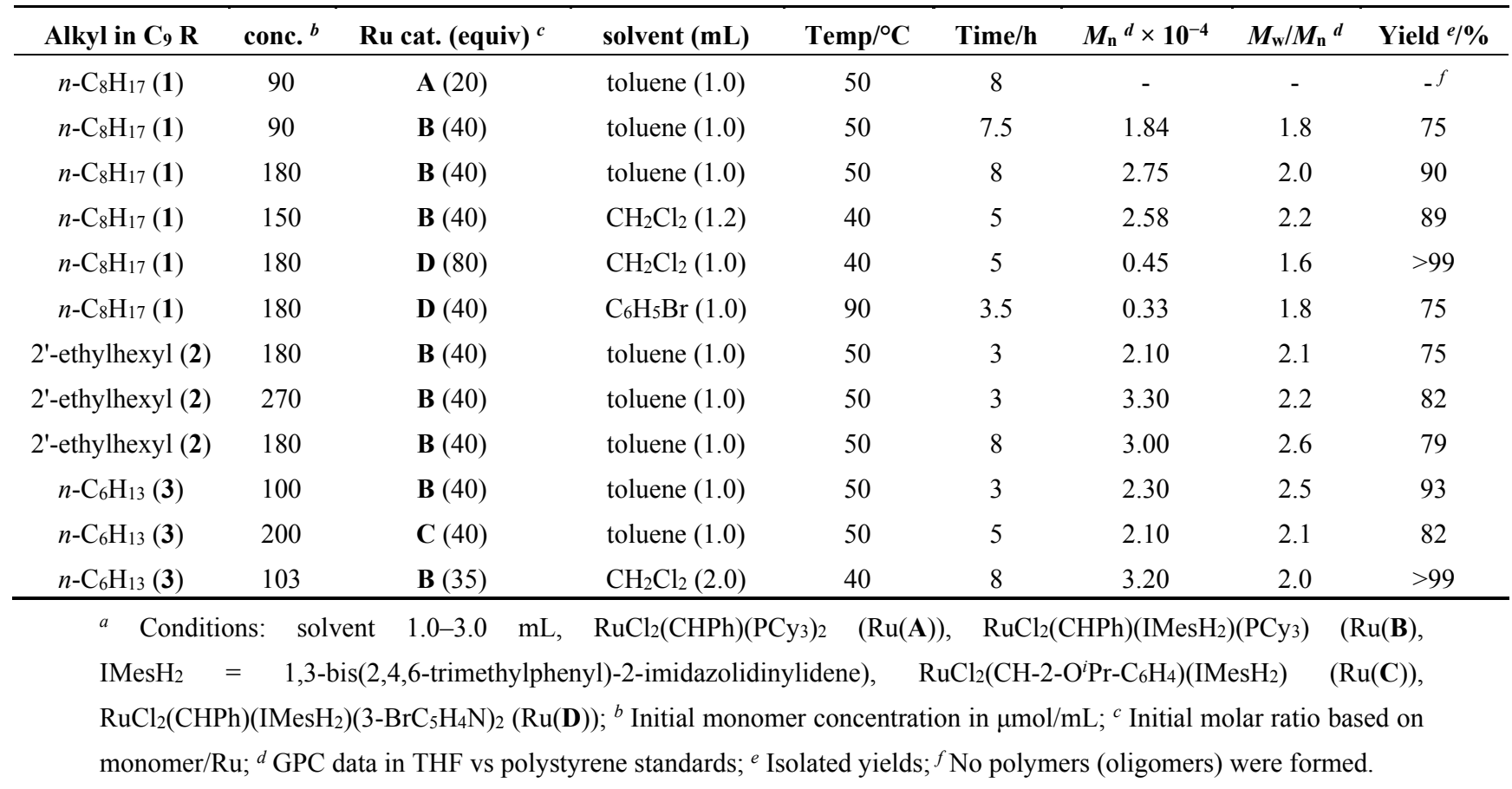

The polymerizations of 2,7-divinyl-9,9-di- $n$-octyl-fluorene using $\mathrm{Ru}(\mathrm{CHPh})(\mathrm{Cl})_{2}\left(\mathrm{IMesH}_{2}\right)\left(\mathrm{PCy}_{3}\right)$ $(\mathrm{Ru}(\mathrm{B}))$ in toluene proceeded under the optimized conditions, affording rather high molecular weight polymers with unimodal molecular weight distributions. Dichloromethane could also be used as the solvent, especially in terms of improvement of the solubility in the resultant PFV. The similar results were observed in the ADMET polymerization of the 2'-ethylhexyl analogue. The polymerization did not complete if the $n$-hexyl analogue was used as the monomer under the similar conditions, probably 
due to precipitation of the resultant polymer after a certain period; the polymerization under low initial monomer concentration conditions or in $\mathrm{CH}_{2} \mathrm{Cl}_{2}$ was effective.

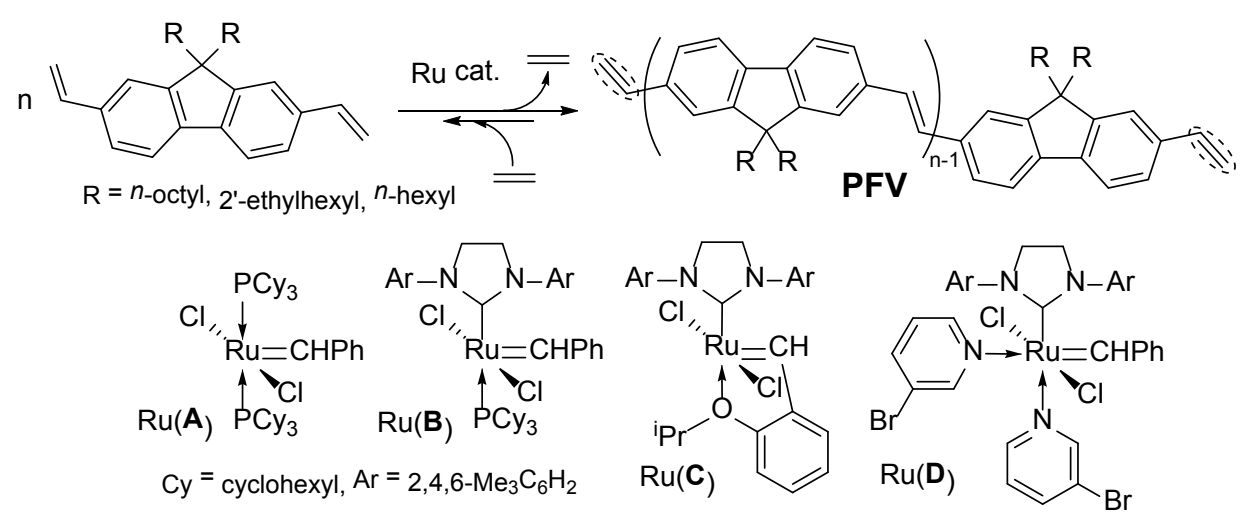

Scheme 4. Acyclic diene metathesis (ADMET) polymerization of 2,7-divinyl-9,9dialkylfluorenes by ruthenium-carbene catalysts [23].

The ADMET polymerization of the $n$-octyl analogue using $\mathrm{RuCl}_{2}(\mathrm{CHPh})(\mathrm{PCy})_{2}[\mathrm{Ru}(\mathbf{A})]$ did not proceed, whereas the polymerization by $\operatorname{Ru}(\mathbf{B})$ afforded high molecular weight polymers under the same conditions. High molecular weight polymers could also be obtained by $\mathrm{RuCl}_{2}\left(\mathrm{CH}-2-\mathrm{O}^{i} \mathrm{Pr}-\right.$ $\left.\mathrm{C}_{6} \mathrm{H}_{4}\right)\left(\mathrm{IMesH}_{2}\right)(\mathrm{Ru}(\mathbf{C}))$. However, the polymerization using $\mathrm{RuCl}_{2}(\mathrm{CHPh})\left(\mathrm{IMesH}_{2}\right)\left(3-\mathrm{BrC}_{5} \mathrm{H}_{4} \mathrm{~N}\right)_{2}$ $(\mathrm{Ru}(\mathrm{D}))$ afforded low molecular weight oligomers even if the reaction was conducted at high temperature $\left(90{ }^{\circ} \mathrm{C}\right)$. This would be explained as due to a formation of the pyridine-coordinated dormant species (probably after formation of the methylidene species, $\mathrm{Ru}=\mathrm{CH}_{2}$ ). Taking into account of these results, it is clear that $\operatorname{Ru}(\mathbf{B})$ and $\operatorname{Ru}(\mathbf{C})$ are suited to this polymerization [23].

Figure 1 shows typical ${ }^{1} \mathrm{H}$ NMR spectrum in the resultant polymer prepared by the ADMET polymerization using ruthenium-carbene catalyst [25]. Olefinic double bonds in the resultant PFVs possessed exclusive trans regularity confirmed by ${ }^{1} \mathrm{H}$ NMR spectra [21,23], because the reaction proceeds via metallacyclobutane intermediate (Scheme 3). Moreover, the resultant PFVs prepared by $\mathrm{Ru}$ catalysts possessed vinyl groups at the both polymer chain ends [22,23,25]. These are remarkable contrasts with that prepared by the previous (precursor) method, especially two broad resonances ascribed to protons at 4.5-4.8 $\mathrm{ppm}$ in addition to rather broad resonances ascribed to aromatic protons in the polymer prepared by the precursor method [23].

Figure 2a shows UV-vis spectra (in THF, $1.0 \times 10^{-5} \mathrm{M}$ at $25^{\circ} \mathrm{C}$ ) for PFVs ( $n$-hexyl analogue) prepared by the ordinary method [available from Aldrich, $M_{\mathrm{n}}=24,100, M_{\mathrm{w}} / M_{\mathrm{n}}=1.70$ and $M_{\mathrm{n}}=1720$, $M_{\mathrm{w}} / M_{\mathrm{n}}=1.11$, prepared from the sulfonium salt precursor monomer under high-temperature $\left(180-300{ }^{\circ} \mathrm{C}\right)$ and vacuum conditions $\left.\left(10^{-6} \mathrm{mbar}\right)\right]$, and by the ADMET polymerization using $\mathrm{Ru}(\mathbf{B})$ $\left(M_{\mathrm{n}}=32,000, M_{\mathrm{w}} / M_{\mathrm{n}}=2.0\right)$. The spectrum prepared by the ADMET polymerization displays two absorption bands at 427 and $455 \mathrm{~nm}$, which can also be attributed to $\pi-\pi *$ transitions of the conjugated backbone [31]. Three absorption peaks at 455,427 , and $400 \mathrm{~nm}$ are attributed to $0-0,0-1$, and $0-2$ transitions [32], respectively, with corresponding emission peaks at 465, 496, and $530 \mathrm{~nm}$ (described below, Figure $2 b$ ). The sample prepared by the ADMET polymerization showed a rather sharp contrast to that prepared by the Hormer-Emmons (HWE) route [reaction of 2,7-bis(methylenediethyl phosphate)-9,9-di-n-octylfluoene with 9,9-di-n-octylfluorene-2,7-dicarbaldehyde in the presence of 
$\mathrm{KO}^{t} \mathrm{Bu}$ ] [31], probably because that the resultant polymer possessed higher stereo-regularity (all trans in the internal olefinic double bond) than that prepared by the HWE route (mixture of cis/trans). Note that the spectrum prepared by the ordinary method (the precursor route) shows a broad absorption band with $\lambda_{\max }=414 \mathrm{~nm}$; this band can be attributed to $\pi-\pi^{*}$ transitions of the conjugated backbones with a shoulder at $c a .380 \mathrm{~nm}$; the bands for the samples prepared by the ADMET polymerization are intensified and red-shifted when compared to that for the sample prepared by the precursor method. The observed difference is due to presence of defect, leading to an enhanced conjugation length [31].

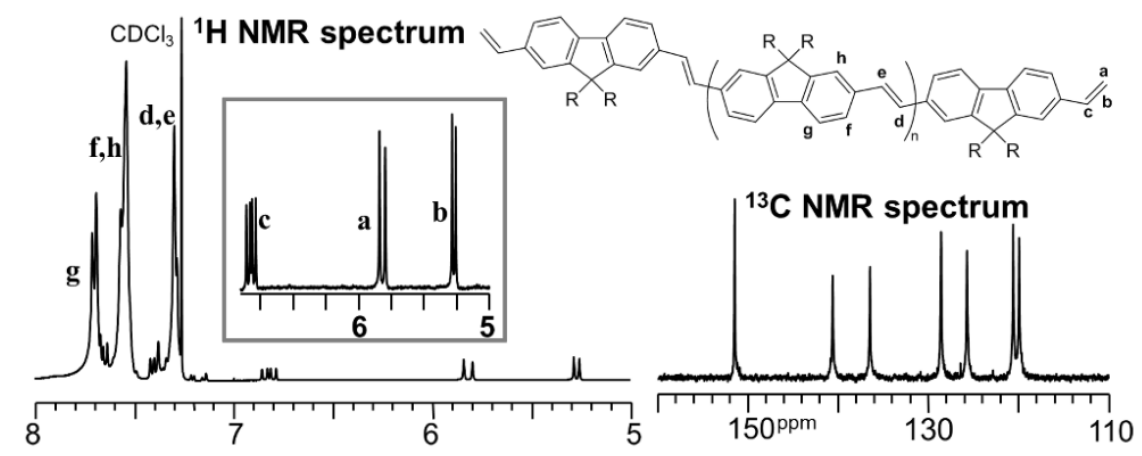

Figure 1. ${ }^{1} \mathrm{H}$ and ${ }^{13} \mathrm{C}$ NMR spectrum (in $\mathrm{CDCl}_{3}$ at $25{ }^{\circ} \mathrm{C}$ ) of poly(9,9-di- $n$-octyl-fluorene vinylene) (PFV) prepared by ADMET polymerization using ruthenium catalyst [25].
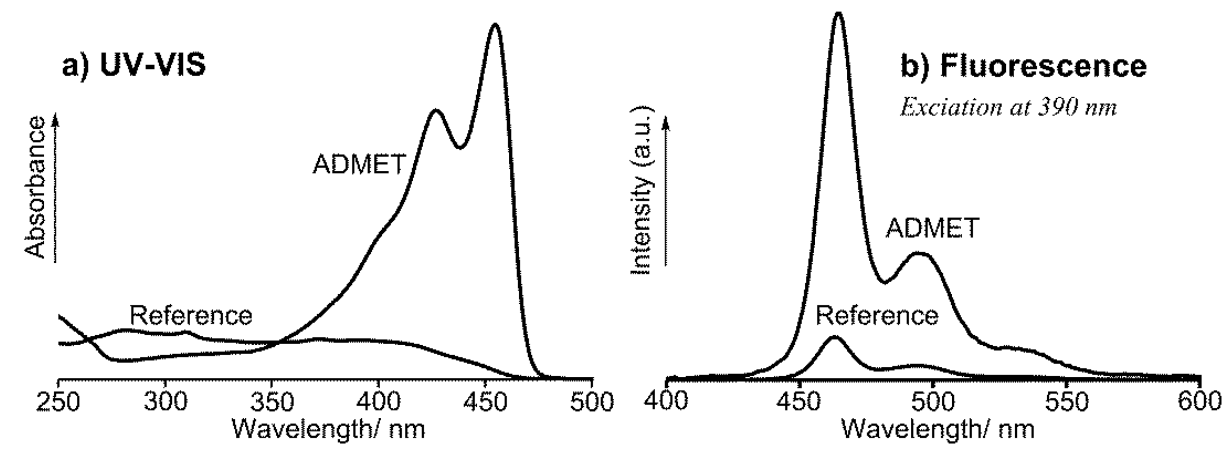

Figure 2. (a) UV-vis (conc. $1.0 \times 10^{-5} \mathrm{M}$ ) and (b) fluorescent (conc. $1.0 \times 10^{-6} \mathrm{M}$ ) spectra for PFVs in THF at $25^{\circ} \mathrm{C}\left(R=n-\mathrm{C}_{6} \mathrm{H}_{13}\right.$; ADMET: $M_{\mathrm{n}}=32,000, M_{\mathrm{w}} / M_{\mathrm{n}}=2.0$; Reference (Aldrich, St. Louis, MO, USA): $M_{\mathrm{n}}=24,100, M_{\mathrm{w}} / M_{\mathrm{n}}=1.70$ and $M_{\mathrm{n}}=1720$, $\left.M_{\mathrm{w}} / M_{\mathrm{n}}=1.11\right)$ [23]. The $M_{\mathrm{n}}$ and the $M_{\mathrm{w}} / M_{\mathrm{n}}$ values were measured by GPC $v s$. polystyrene standards.

Figure $2 \mathrm{~b}$ shows the fluorescence spectra (in THF, $1.0 \times 10^{-6} \mathrm{M}$ at $25{ }^{\circ} \mathrm{C}$, excitation wavelength at $390 \mathrm{~nm}$ or $426 \mathrm{~nm}$ ). The spectrum of PFV prepared by the ADMET method showed a strong emission band at $465 \mathrm{~nm}$ with a shoulder at $496 \mathrm{~nm}$ along with a slight shoulder at $530 \mathrm{~nm}$. It is explained that the shoulder arises from coupling between the fluorene and vinylene units to form a new electronic state with a lower energy. No significant differences were observed in the spectra for the other alkyl analogues [23]. The spectrum of PFV prepared by the precursor route also showed a rather strong emission band at $464 \mathrm{~nm}$ with a shoulder at $494 \mathrm{~nm}$, but remarkable differences in their intensities were seen. Moreover, a shoulder observed at $450 \mathrm{~nm}$ in the sample prepared by the HWE route was not observed in the samples prepared by the ADMET route and the emission band at $465 \mathrm{~nm}$ possessed 
narrow half-width. The observed difference would be probably due to that the resultant polymer possessed high stereo-regularity (all trans olefinic double bond) without any defects. Therefore, it is clear that PFVs prepared by the ADMET polymerization are defect-free polymers with high stereo-regularity as well as with better optical property compared with samples prepared by the other methods.

\section{Modification of Conjugated Polymers by Exclusive End-Functionalization}

Since the resultant polymers prepared by the ADMET polymerization using Ru catalyst possess well-defined chain ends as vinyl group [22,23], a facile, exclusive end-functionalization can be achieved by treating the vinyl groups with molybdenum-alkylidene, $\mathrm{Mo}(\mathrm{CHCMe} 2 \mathrm{Ph})(\mathrm{N}-2,6-$ $\left.\mathrm{Me}_{2} \mathrm{C}_{6} \mathrm{H}_{3}\right)\left[\mathrm{OCMe}\left(\mathrm{CF}_{3}\right)_{2}\right]_{2}$ (Mo cat.) followed by Wittig-type cleavage with aldehyde [25-30,33-35].

A facile, exclusive end-functionalization of PFV prepared by ADMET polymerization using $\operatorname{Ru}(\mathbf{B})$ has been achieved by treating the vinyl groups in PFV chain ends with Mo cat. followed by Wittigtype cleavage with 4- $\mathrm{Me}_{3} \mathrm{SiOC}_{6} \mathrm{H}_{4} \mathrm{CHO}$; precise synthesis of ABA type amphiphilic triblock copolymers could be accomplished by grafting PEG into both the PFV chain ends (Scheme 5) [25].

The SiMez group in the resultant polymers (PFV-OTMS) was easily cleaved by treating with $\mathrm{HCl}$ aq. to afford PFV-OH in high yields. No significant changes in the $M_{\mathrm{n}}$ values were seen before/after the procedure. The $\mathrm{OH}$ groups in the PFV chain ends were then treated with $\mathrm{KH}$ in THF, and the subsequent reaction with mesylated poly(ethylene glycol) (PEGMs2) gave ABA-type amphiphilic triblock copolymers in rather high yields $(69 \%-90 \%)$. The resultant copolymers possessed uniform molecular weight distributions; the copolymers were identified by ${ }^{1} \mathrm{H}$ (Figure 3 ) and ${ }^{13} \mathrm{C}$ NMR spectra and confirmed that no residual PEG was seen in GPC traces for the isolated polymer(s). The $M_{\mathrm{n}}$ values in the resultant triblock copolymers estimated based on the integration ratios with methylene protons of the PEG segment (Figure $3 b$ ) were very close to those estimated by both GPC $\left[M_{\mathrm{n} \text { (calc.) }}=M_{\mathrm{n}(\mathrm{GPC})} / 1.6\right]$ and the value in the starting PEG [25].

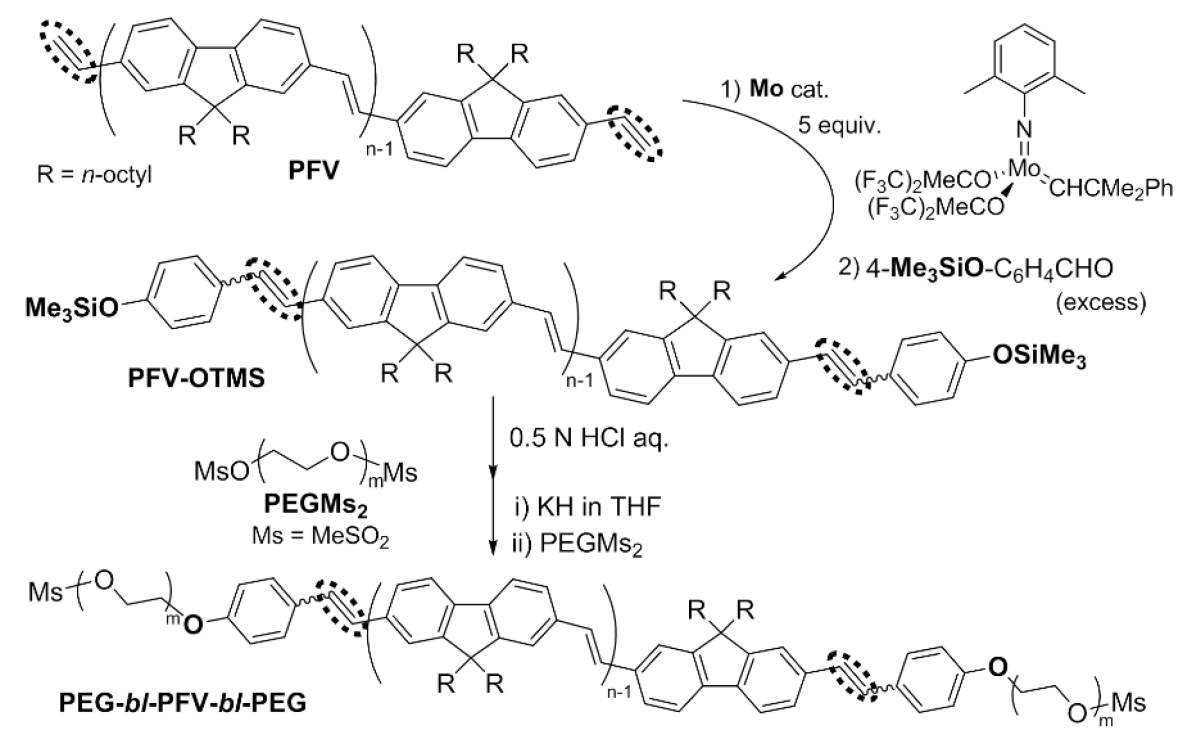

Scheme 5. Synthesis of amphiphilic triblock copolymers [25]. 

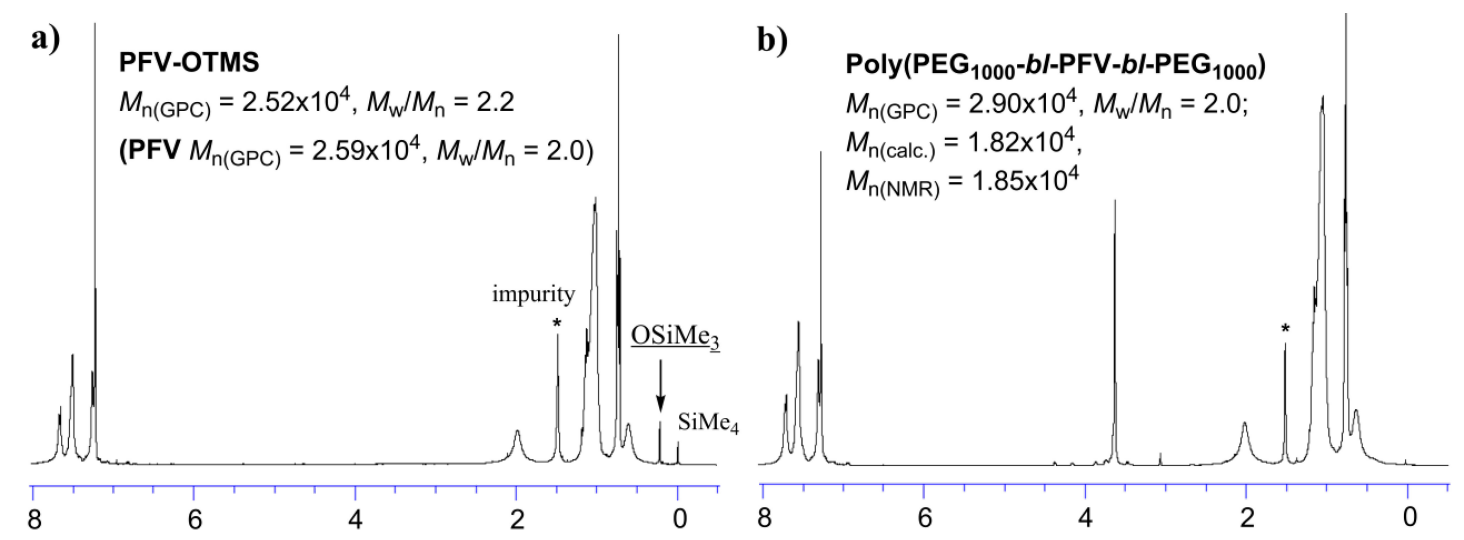

Figure 3. ${ }^{1} \mathrm{H}$ NMR spectra (in $\mathrm{CDCl}_{3}$ at $25^{\circ} \mathrm{C}$ ) for (a) PFV-OTMS and (b) PEG-bl-PFV-bl-PEG [25].

Various block (graft) copolymers have been prepared by combination of the ADMET polymerization of 9,9-dialkyl-2,7-divinyl-fluorene with $\mathrm{Cu}$-catalyzed atom transfer radical polymerization (ATRP) of styrene using macroinitiators prepared by an introduction of initiating functionalities into PFVs chain ends (Scheme 6) [27]. The $M_{\mathrm{n}}$ value in the macroinitoator, $\mathrm{PFV}\left(\mathrm{C}_{6} \mathrm{H}_{4} \mathrm{OCOCMe} 2 \mathrm{Br}\right)_{2}$, estimated by ${ }^{1} \mathrm{H}$ NMR spectra, was relatively close to that estimated based on the exact $M_{\mathrm{n}}$ value of PFV (corrected from GPC data), strongly suggesting that both polymer chain ends could be exclusively modified by adopting the present approach. The resultant macroinitiator was added in styrene in the presence of $\mathrm{CuBr}$, dNbipy (4,4-dinonyl-2,2-dipyridyl) at $90{ }^{\circ} \mathrm{C}$ for conducting subsequent ATRP. A precise synthesis of the amphiphilic ABCBA-type block copolymers could be then attained by subsequent combination with click reaction after modification of the chain end with $\mathrm{NaN}_{3} .{ }^{1} \mathrm{H}$ NMR spectra for the resultant polymers possessed protons ascribed to PEG units, suggesting incorporation of PEG segment. Note that the $M_{\mathrm{n}}$ values estimated by ${ }^{1} \mathrm{H}$ NMR spectra (on the basis of methylene protons in the PEG segment) were very close to those calculated (based on $M_{\mathrm{n}}$ value of PFV and integration ratio of PFV and styrene). The formation of regular one-dimensional conjugated structures on the nanoscale should be thus expected by exploiting the specific assembling properties of rod-coil block copolymers, and the precise control of the amphiphilic nature as well as of the block lengths via synthesis shall open the way to fine-tuning the lateral dimensions of these nanostructures.

\subsection{Precise One-Pot Synthesis of End-Functionalized Conjugated Multi-Block Copolymers via Combined Olefin Metathesis and Wittig-Type Coupling}

Emerging applications of conjugated polymers require the patterning of materials on the nm length scale, and block copolymers made of covalently linked polymers represent an ideal route to control the self-assembly of these nano-sized morphologies. Formation of regular one-dimensional conjugated structures on the nano-scale should be thus expected by exploiting the specific assembling properties of rod-coil block copolymers, and a precise control of the block lengths via synthesis shall open the way to fine-tuning the lateral dimensions of these nano-structures. However, the vast majority of a significant number of studies for the generation of nano-scale morphologies from block copolymers have involved one or more of the blocks on the basis of random copolymers or random copolymers with conjugated units attached as side chains. Therefore, more relevant systems would be envisaged based on fully conjugated block copolymers from an application and scientific viewpoints. 


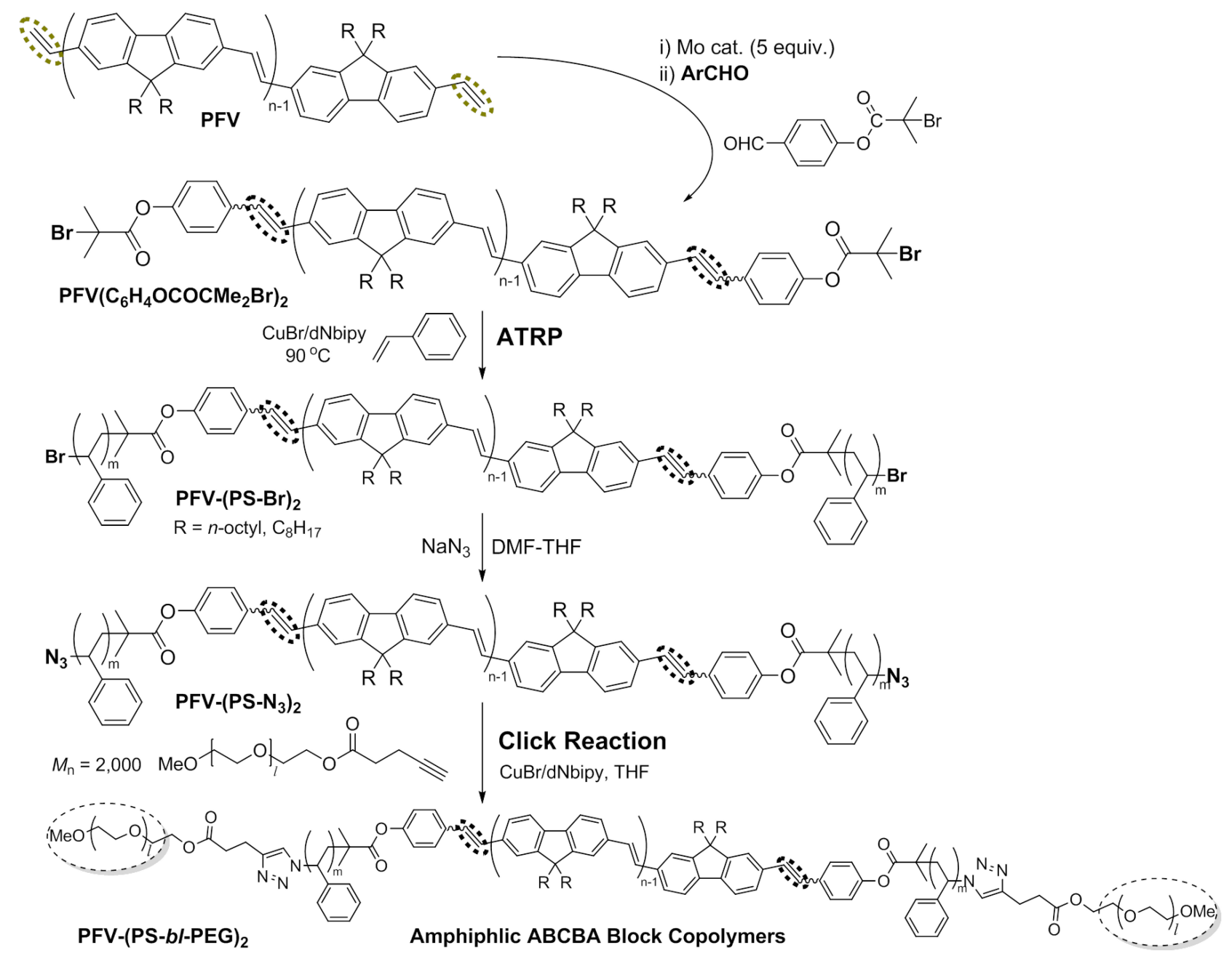

Scheme 6. Syntheses of macroinitiator, block copolymers by combination of ADMET polymerization with $\mathrm{Cu}$ catalyzed atom transfer radical polymerization (ATRP). Synthesis of amphiphilic ABCBA block copolymers, PFV-(PS-bl-PEG)2, by combination of ATRP with click coupling [27].

A precise, one-pot synthesis of end-functionalized block copolymers consisting of PFVs and oligo(2,5-dialkoxy-1,4-phenylene vinylene) or terthiophene units as the middle segment could be prepared by olefin metathesis of the vinyl group in the PFV chain ends followed by subsequent Wittig-type coupling [29]. As shown in Scheme 7, two approaches were considered for this purpose. In method A, the vinyl groups in the PFVs' chain ends were treated with $\mathrm{Mo}\left(\mathrm{CHCMe}_{2} \mathrm{Ph}\right)$ $\left(\mathrm{N}-2,6-\mathrm{Me}_{2} \mathrm{C}_{6} \mathrm{H}_{3}\right)\left[\mathrm{OCMe}\left(\mathrm{CF}_{3}\right)_{2}\right]_{2}$ (Mo cat., 5 equiv) to afford the "bis-alkylidene" species in situ, which were isolated by washing with cold $n$-hexane. Then, 0.5 equiv of $7 \mathrm{PVCHO}$ [7mer of (2,5-dialkoxy-1,4-phenylene vinylene) with $\mathrm{CHO}$ as the chain end] [34] or 3T(CHO 2 was added into the toluene solution containing the "bis-alkylidene" species. The subsequent addition of excess amount of aldehyde (ArCHO) afforded end-functionalized triblock copolymers, expressed as [(PFV) 7PV]Ar 2 or $\left[(\mathbf{P F V})_{2}-3 \mathbf{T}\right] \mathbf{A r}_{2}\left(\mathrm{Ar}=\mathrm{C}_{6} \mathrm{H}_{5}, \mathrm{C}_{6} \mathrm{~F}_{5}, 4-\mathrm{Me}_{3} \mathrm{SiO}_{-} \mathrm{C}_{6} \mathrm{H}_{4}\right.$, terthiophene (3T), ferrocene (Fc), bipyridyl (bpy)), from moderate to high yields (38-89\% yields on the basis of PFVs, Table 2), which were isolated simply by pouring the reaction mixture into methanol. The $M_{\mathrm{n}}$ values in $\left[(\mathbf{P F V})_{2}\right.$ 7PV]Ar, 
[(PFV) $)_{2}-3$ T $]$ Ar $_{2}$ were analogous to the estimated values with unimodal molecular weight distributions $\left(M_{\mathrm{w}} / M_{\mathrm{n}}=1.14-1.36\right.$, Table 2$)$ without significant increases after these modification procedures. Resonances ascribed to protons of the vinyl groups in the starting PFVs were not observed in the ${ }^{1} \mathrm{H}$ NMR spectra, whereas resonances ascribed to protons in the middle segment, especially $\mathbf{7 P V}$, were clearly observed. Moreover, the estimated $M_{\mathrm{n}}$ values on the basis of integration (of the middle segments, expressed as $M_{\mathrm{n}(\mathrm{NMR})}$ in Table 2) were highly analogous to the calculated values [expressed as $M_{\mathrm{n} \text { (calcd) }}$ in Table 2] on the basis of molar ratios.

As a more facile "one-pot" procedure for the synthesis (expressed as method B), the vinyl groups in the PFVs' chain ends were treated with Mo cat. (1.8 equiv to PFV) to afford the "bis-alkylidene" species containing "mono-alkylidene" species partially in situ. The mixture was then added a dichloromethane solution containing 0.5 equiv of OPVCHO (3PVCHO, 7PVCHO) or 3T(CHO)2. The resultant reaction mixture was added into a toluene solution containing Mo cat (2.5 equiv) to complete the olefin metathesis (with the vinyl group in the PFV chain ends), and the subsequent addition of aldehyde (ArCHO) in excess amount afforded end-functionalized triblock copolymers, expressed as [(PFV) $\left.)_{2}-\mathbf{7 P V}\right] \mathbf{A r} \mathbf{r}_{2}$, [(PFV) $\left.)_{2}-\mathbf{3 P V}\right] \mathbf{A r}_{2}$ or $\left[(\mathbf{P F V})_{2}-\mathbf{3 T}\right] \mathbf{A r} \mathbf{r}_{2}\left(\mathrm{Ar}=\mathrm{C}_{6} \mathrm{H}_{5}, \mathrm{C}_{6} \mathrm{~F}_{5}\right.$, terthiophene (3T), ferrocene $(\mathrm{Fc}))$, in high yields $(70 \%-88 \%$ yields on the basis of PFVs, Table 2$)$, which were isolated simply by pouring the reaction mixture into methanol. The $M_{\mathrm{n}}$ values in $\left[(\mathbf{P F V})_{\mathbf{2}} \mathbf{- 7 P V}\right] \mathbf{A r} \mathbf{r}_{2}$, [(PFV $)_{2}-3$ T $] \mathbf{A r}_{2}$ were analogous to the estimated values with uniform molecular weight distributions $\left(M_{\mathrm{w}} / M_{\mathrm{n}}=1.33-1.63\right)$ without significant increases after these modification procedures, and were close to those adopted in the above approach (method A). Moreover, resonances ascribed to protons of the vinyl groups in the starting PFVs were not observed in the ${ }^{1} \mathrm{H}$ NMR spectra, whereas resonances ascribed to protons in the middle segment, especially $\mathbf{7 P V}$ or 3PV, were clearly observed (Figure 4). Moreover, the estimated $M_{\mathrm{n}}$ values on the basis of integration [of the middle segments, expressed as $M_{\mathrm{n}(\mathrm{NMR})}$ ] were highly analogous to the calculated values [expressed as $M_{\mathrm{n}(\mathrm{calcd})}$ ] on the basis of molar ratios. These results also strongly suggest that exclusive formations of $\left[(\mathbf{P F V})_{2}-\mathbf{7 P V}\right] \mathbf{A r} \mathbf{2}_{2},\left[(\mathbf{P F V})_{\mathbf{2}^{-}}\right.$ 3PV]Ar ${ }_{2},\left[(\mathbf{P F V})_{2}-3 \mathbf{3 T}_{2} \mathbf{A r}_{2}\right.$ have been achieved by adopting this methodology. The latter method should be more promising and useful, because the target end-functionalized fully conjugated block copolymers can be easily prepared in one-pot in a precise manner.

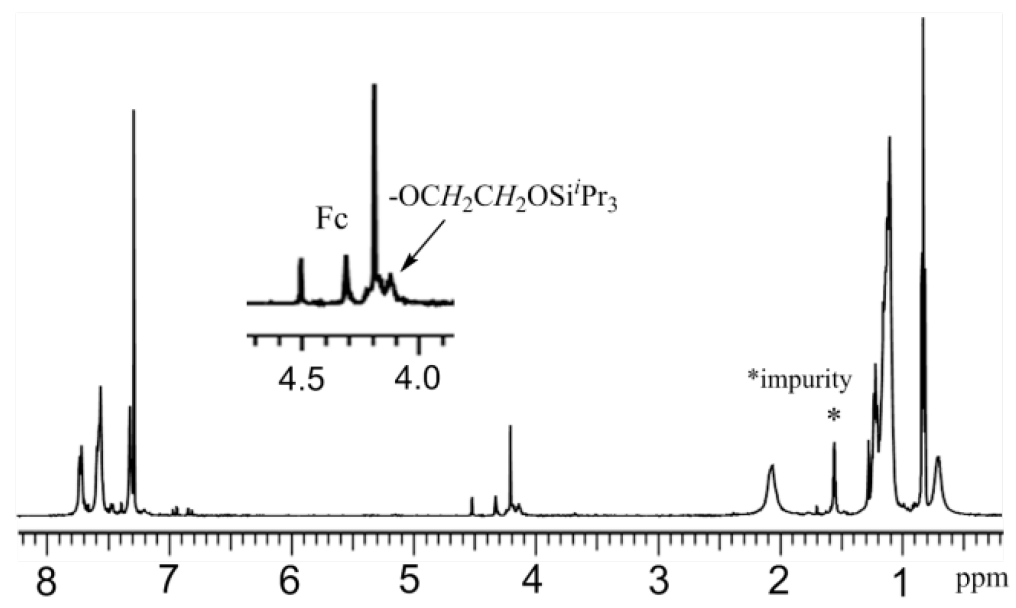

Figure 4. ${ }^{1} \mathrm{H}$ NMR spectrum (in $\mathrm{CDCl}_{3}$ at $\left.25{ }^{\circ} \mathrm{C}\right)$ for $\left[(\mathbf{P F V})_{2}-\mathbf{3 P V}\right](\mathbf{F c})_{2}\left(M_{\mathrm{n}(\mathrm{NMR})}=9000\right)[29]$. 


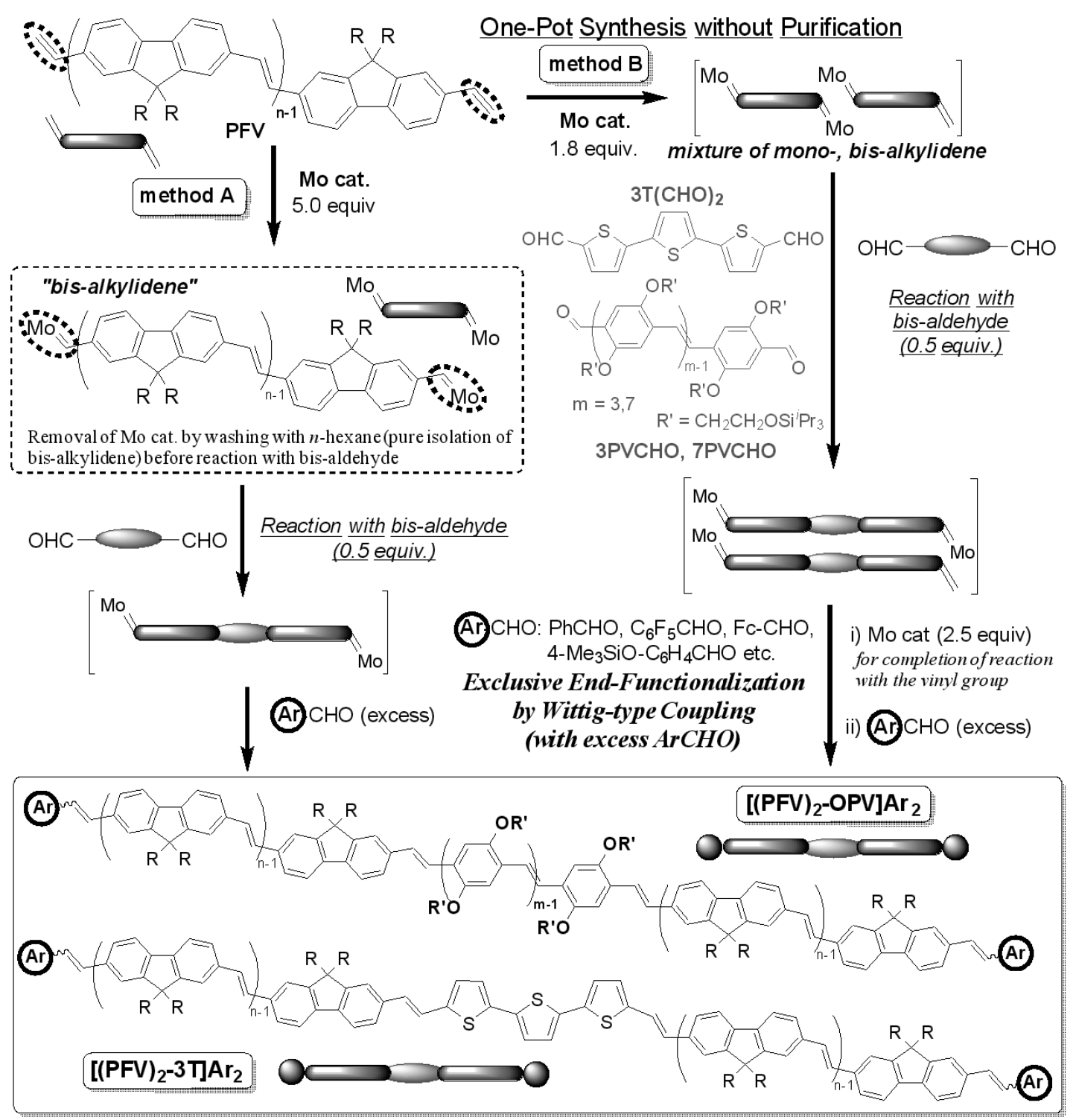

Scheme 7. Synthesis of end-functionalized triblock conjugated copolymers [29].

The resultant block copolymers containing phenolic moiety protected as $\mathrm{SiMe}_{3}$ group in the chain ends, [(PFV) $\left.)_{2}-7 \mathrm{PV}\right]\left(4-\mathrm{OSiMe}_{3}-\mathrm{C}_{6} \mathrm{H}_{4}\right)_{2},\left[(\mathrm{PFV})_{2}-3 \mathrm{~T}\right]\left(4-\mathrm{OSiMe}_{3}-\mathrm{C}_{6} \mathrm{H}_{4}\right)_{2}$, were treated with $\mathrm{HCl}$ aq. to

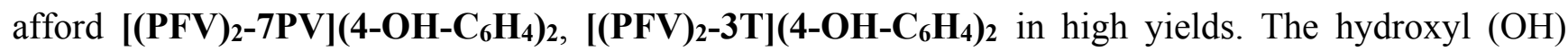
groups in the PFV chain ends were then treated with $\mathrm{KH}$ in THF and the subsequent reaction with mesylated poly(ethylene glycol) [PEGMs2, $\mathrm{MsO}\left(\mathrm{CH}_{2} \mathrm{CH}_{2} \mathrm{O}\right)_{n} \mathrm{Ms}, \mathrm{Ms}=\mathrm{MeSO}_{2}: M_{\mathrm{n}}=4600$ ] gave ABCBA type amphiphilic block copolymers in moderate yields (60,75\%, Scheme 8). The resultant copolymers possessed uniform molecular weight distributions; the copolymers were identified by ${ }^{1} \mathrm{H}$ NMR spectra and confirmed that no residual PEG was seen in GPC traces for the isolated polymer(s). The $M_{\mathrm{n}}$ values in the resultant block copolymers estimated based on the integration ratios with methylene protons of the PEG segment were very close to the calculated values (Table 3). The facts clearly indicate that facile, efficient attachments of a pseudo phenol terminus on the PFV to PEGMs2, could be achieved in a precise manner by adopting the present "grafting to" approach. Moreover, importantly, the results strongly demonstrate that the end-functionalization of PFV chain ends, 
reaction with the middle segments, and subsequent grafting of PEG took place with exclusively in all cases.

Table 2. Synthesis of triblock copolymers with well-defined end functional groups [29].

\begin{tabular}{|c|c|c|c|c|c|c|c|c|}
\hline \multirow{2}{*}{ Polymers } & \multicolumn{2}{|c|}{ PFV $^{a}$} & \multirow{2}{*}{$\begin{array}{c}\text { Method } \\
\text { A or B } \\
\end{array}$} & \multicolumn{4}{|c|}{ Polymer } & \multirow{2}{*}{ Yield $^{e} / \%$} \\
\hline & $M_{\mathrm{n}(\mathrm{GPC})^{b}}$ & $M_{\mathrm{n} \text { (calcd) }}$ & & $M_{\mathrm{n}(\mathrm{GPC})}{ }^{b}$ & $M_{\mathrm{n}(\text { calcd })}{ }^{c}$ & $M_{\mathrm{n}(\mathrm{NMR})}{ }^{d}$ & $M_{\mathrm{w}} / M_{\mathrm{n}}{ }^{b}$ & \\
\hline$\left[(\mathrm{PFV})_{2}-7 \mathrm{PV}\right]\left(\mathrm{C}_{6} \mathrm{H}_{5}\right)_{2}$ & $7,300^{f}$ & 4,560 & $\mathrm{~A}$ & 19,400 & 13,000 & 12,700 & 1.15 & 38 \\
\hline$\left[(\mathrm{PFV})_{2}-7 \mathrm{PV}\right]\left(\mathrm{C}_{6} \mathrm{~F}_{5}\right)_{2}$ & $7,300^{f}$ & 4,560 & A & 20,300 & 13,200 & 12,800 & 1.16 & 54 \\
\hline$\left[(\mathrm{PFV})_{2}-7 \mathrm{PV}\right]\left(4-\mathrm{OSiMe}_{3}-\mathrm{C}_{6} \mathrm{H}_{4}\right)_{2}$ & $7,300^{f}$ & 4,560 & A & 19,200 & 13,200 & 12,800 & 1.14 & 62 \\
\hline$\left[(\mathrm{PFV})_{2}-7 \mathrm{PV}\right](3 \mathrm{~T})_{2}$ & $7,300^{f}$ & 4,560 & A & 20,400 & 13,300 & 13,100 & 1.16 & 42 \\
\hline$\left[(\mathrm{PFV})_{2}-7 \mathrm{PV}\right](\mathrm{Fc})_{2}$ & $7,300^{f}$ & 4,560 & A & 20,600 & 13,200 & 12,900 & 1.17 & 42 \\
\hline$\left[(\mathbf{P F V})_{2}-7 \mathrm{PV}\right]\left(\mathrm{C}_{6} \mathrm{H}_{5}\right)_{2}$ & $14,000^{g}$ & 8,750 & A & 33,400 & 21,300 & - & 1.32 & 75 \\
\hline$\left[(\mathrm{PFV})_{2}-7 \mathrm{PV}\right]\left(\mathrm{C}_{6} \mathrm{~F}_{5}\right)_{2}$ & $14,000^{g}$ & 8,750 & A & 38,500 & 21,500 & - & 1.36 & 85 \\
\hline$\left[(\mathrm{PFV})_{2}-7 \mathrm{PV}\right]\left(4-\mathrm{OSiMe}_{3}-\mathrm{C}_{6} \mathrm{H}_{4}\right)_{2}$ & $14,000^{g}$ & 8,750 & A & 30,800 & 21,500 & 21,700 & 1.31 & 87 \\
\hline$\left[(\mathrm{PFV})_{2}-7 \mathrm{PV}\right](\mathrm{bpy})_{2}$ & $14,000^{g}$ & 8,750 & A & 32,000 & 21,500 & - & 1.32 & 53 \\
\hline$\left[(\mathrm{PFV})_{2}-7 \mathrm{PV}\right]\left(\mathrm{C}_{6} \mathrm{H}_{5}\right)_{2}$ & $8,080^{h}$ & 5,050 & B & 19,700 & 13,900 & 12,100 & 1.50 & 73 \\
\hline$\left[(\mathrm{PFV})_{2}-7 \mathrm{PV}\right]\left(\mathrm{C}_{6} \mathrm{~F}_{5}\right)_{2}$ & $8,080^{h}$ & 5,050 & B & 20,800 & 14,100 & 12,300 & 1.57 & 80 \\
\hline$\left[(\mathbf{P F V})_{2}-7 \mathrm{PV}\right](3 \mathrm{~T})_{2}$ & $8,080^{h}$ & 5,050 & B & 19,200 & 14,400 & 12,500 & 1.43 & 88 \\
\hline$\left[(\mathrm{PFV})_{2}-7 \mathrm{PV}\right](\mathrm{Fc})_{2}$ & $8,080^{h}$ & 5,050 & B & 20,300 & 14,200 & 12,300 & 1.33 & 75 \\
\hline$\left[(\mathrm{PFV})_{2}-3 \mathrm{~T}\right]\left(\mathrm{C}_{6} \mathrm{H}_{5}\right)_{2}$ & $7,300^{f}$ & 4,560 & A & 17,600 & 9,500 & - & 1.22 & 72 \\
\hline$\left[(\mathrm{PFV})_{2}-3 \mathrm{~T}\right]\left(4-\mathrm{OSiMe}_{3}-\mathrm{C}_{6} \mathrm{H}_{4}\right)_{2}$ & $7,300^{f}$ & 4,560 & A & 19,800 & 9,600 & 9,400 & 1.19 & 64 \\
\hline$\left[(\mathrm{PFV})_{2}-3 \mathrm{~T}\right]\left(\mathrm{C}_{6} \mathrm{~F}_{5}\right)_{2}$ & $7,300^{f}$ & 4,560 & A & 18,800 & 9,600 & - & 1.31 & 80 \\
\hline$\left[(\mathrm{PFV})_{2}-3 \mathrm{~T}\right](3 \mathrm{TT})_{2}$ & $7,300^{f}$ & 4,560 & A & 16,000 & 9,800 & - & 1.29 & 32 \\
\hline$\left[(\mathbf{P F V})_{2}-3 \mathrm{~T}\right](\mathbf{F c})_{2}$ & $7,300^{f}$ & 4,560 & A & 18,800 & 9,700 & 9,400 & 1.16 & 60 \\
\hline$\left[(\mathrm{PFV})_{2}-3 \mathrm{TT}\right](3 \mathrm{TT})_{2}$ & $8,080^{h}$ & 5,050 & B & 15,400 & 10,800 & - & 1.63 & 70 \\
\hline$\left[(\mathrm{PFV})_{2}-3 \mathrm{PV}\right]\left(\mathrm{C}_{6} \mathrm{~F}_{5}\right)_{2}$ & $6,380^{i}$ & 3,990 & B & 26,600 & 9,900 & 8,900 & 1.50 & 76 \\
\hline$\left[(\mathrm{PFV})_{2}-3 \mathrm{PV}\right](\mathrm{Fc})_{2}$ & $6,380^{i}$ & $3,990^{i}$ & B & 22,900 & 9,900 & 9,000 & 1.50 & 71 \\
\hline$\left[(\mathrm{PFV})_{2}-3 \mathrm{TT}\right]\left(\mathrm{C}_{6} \mathrm{H}_{5}\right)_{2}$ & $14,000^{g}$ & 8,750 & A & 26,300 & 17,800 & - & 1.19 & 73 \\
\hline$\left[(\mathrm{PFV})_{2}-3 \mathrm{~T}\right]\left(4-\mathrm{OSiMe}_{3}-\mathrm{C}_{6} \mathrm{H}_{4}\right)_{2}$ & $14,000^{g}$ & 8,750 & A & 23,300 & 18,000 & 18,200 & 1.16 & 78 \\
\hline$\left[(\mathrm{PFV})_{2}-3 \mathrm{~T}\right]\left(\mathrm{C}_{6} \mathrm{~F}_{5}\right)_{2}$ & $14,000^{g}$ & 8,750 & A & 23,900 & 18,000 & - & 1.15 & 89 \\
\hline$\left[(\mathrm{PFV})_{2}-3 \mathrm{~T}\right](\mathrm{Fc})_{2}$ & $14,000^{g}$ & 8,750 & $\mathrm{~B}$ & 26,500 & 18,000 & 18,300 & 1.39 & 82 \\
\hline
\end{tabular}

${ }^{a}$ PFV (vinyl group chain end) employed for the syntheses. ${ }^{b}$ GPC data in THF vs polystyrene standards.

${ }^{c}$ Calculated on the basis of molar ratio. ${ }^{d}$ Estimated by the integration ratio (middle and end groups). ${ }^{e}$ Isolated yield. ${ }^{f} M_{\mathrm{n}(\mathrm{GPC})}=7300, M_{\mathrm{w}} / M_{\mathrm{n}}=1.86, M_{\mathrm{n}(\mathrm{calcd})}=M_{\mathrm{n}(\mathrm{GPC})} / 1.6=4560$ (by references $\left.[21,28]\right), M_{\mathrm{n}(\mathrm{NMR})}=$ 4400 (estimated by the integration with the vinyl group in the ${ }^{1} \mathrm{H}$ NMR spectrum). ${ }^{g} \mathrm{PFV}$ (vinyl group chain end): $M_{\mathrm{n}(\mathrm{GPC})}=14,000, M_{\mathrm{w}} / M_{\mathrm{n}}=1.60, M_{\mathrm{n}(\mathrm{calcd})}=M_{\mathrm{n}(\mathrm{GPC})} / 1.6=8750, M_{\mathrm{n}(\mathrm{NMR})}=8800($ estimated by the integration with the vinyl group in the ${ }^{1} \mathrm{H}$ NMR spectrum). ${ }^{h} \mathrm{PFV}$ (vinyl group chain end): $M_{\mathrm{n}(\mathrm{GPC})}=8080, M_{\mathrm{w}} / M_{\mathrm{n}}=1.79, M_{\mathrm{n}(\text { calcd) }}=$ $M_{\mathrm{n}(\mathrm{GPC})} / 1.6=5050, M_{\mathrm{n}(\mathrm{NMR})}=4100$ (estimated by the integration with the vinyl group in the ${ }^{1} \mathrm{H}$ NMR spectrum). ${ }^{I}$ PFV (vinyl group chain end): $M_{\mathrm{n}(\mathrm{GPC})}=6380, M_{\mathrm{w}} / M_{\mathrm{n}}=1.99, M_{\mathrm{n}(\mathrm{calcd})}=M_{\mathrm{n}(\mathrm{GPC})} / 1.6=3990, M_{\mathrm{n}(\mathrm{NMR})}=3500$ (estimated by the integration with the vinyl group in the ${ }^{1} \mathrm{H}$ NMR spectrum).

We have shown that a facile, efficient synthesis of ABCBA type amphiphilic block copolymers has been established in a precise manner (as a rare example) by attachment of PEG into the both chain ends of the all-trans, defect-free, high molecular weight PFVs. Formation of regular one-dimensional conjugated structures on the nanoscale should be thus expected by exploiting the specific assembling properties of rod-coil block copolymers, and the control of the block lengths via synthesis opens the way to fine tuning the lateral dimensions of these nanostructures. We thus believe that the present 
approach should offer unique, important methodology for precise synthesis of end functionalized block conjugated polymers for targeted device materials as well as synthesis of various block copolymers containing conjugated polymer fragments.

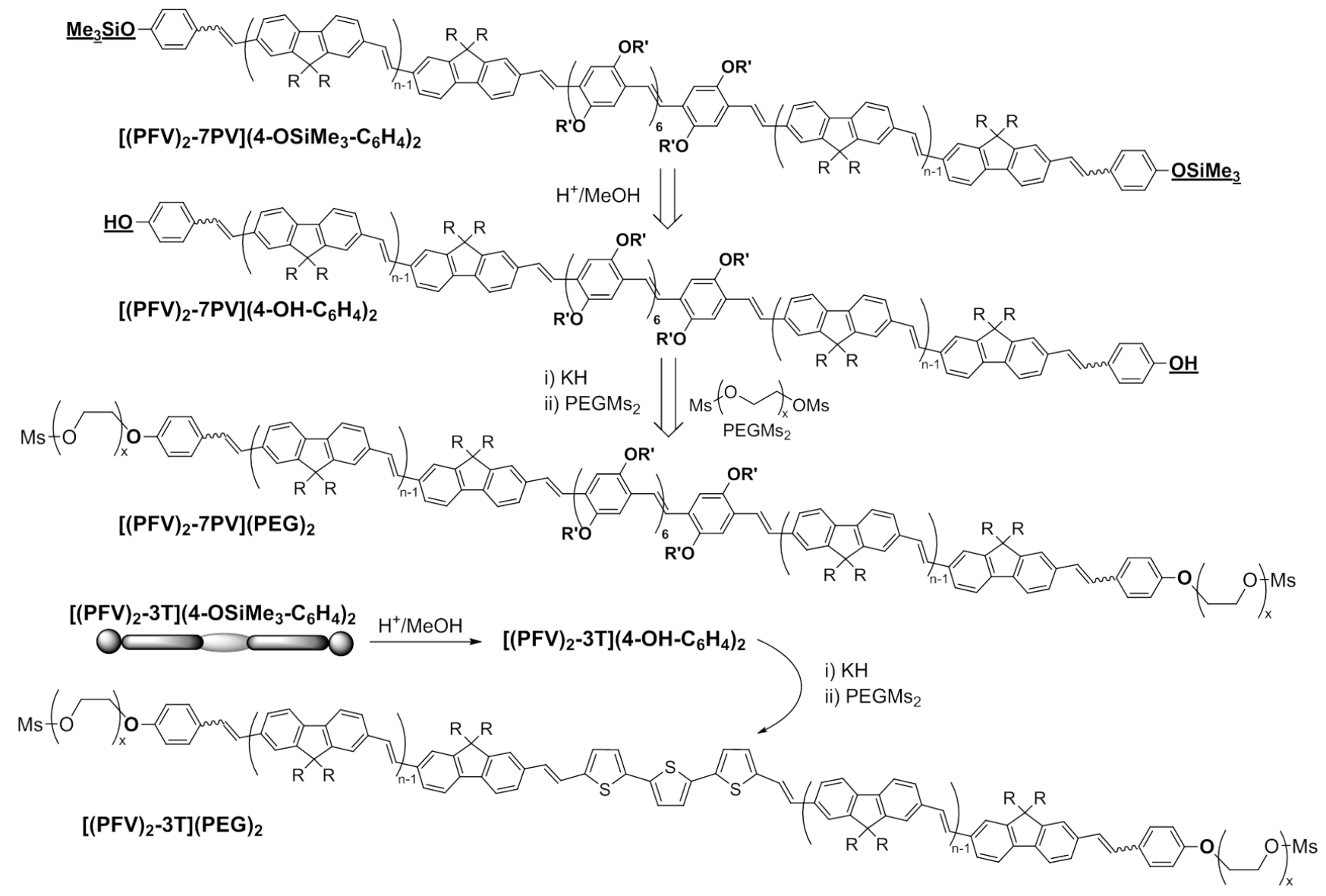

Scheme 8. Synthesis of amphiphilic block copolymers (by grafting PEG) [29].

Table 3. Synthesis of amphiphilic block copolymers by grafting PEG [29] ${ }^{a}$.

\begin{tabular}{|c|c|c|c|c|c|}
\hline Polymers & $M_{\mathrm{n}(\mathrm{GPC})}{ }^{b}$ & $M_{\mathrm{n}(\text { calcd })}{ }^{c}$ & $M_{\mathrm{n}(\mathrm{NMR})}{ }^{d}$ & $M_{\mathrm{w}} / M_{\mathrm{n}}{ }^{b}$ & Yield $^{e} / \%$ \\
\hline$\left[(\mathrm{PFV})_{2}-7 \mathrm{PV}\right]\left(4-\mathrm{OSiMe}_{3}-\mathrm{C}_{6} \mathrm{H}_{4}\right)_{2}$ & 30800 & 21500 & 21700 & 1.31 & 87 \\
\hline$\left[(\mathrm{PFV})_{2}-7 \mathrm{PV}\right]\left(4-\mathrm{OH}-\mathrm{C}_{6} \mathrm{H}_{4}\right)_{2}$ & 32300 & 21400 & - & 1.33 & 85 \\
\hline$\left[(\mathrm{PFV})_{2}-7 \mathrm{PV}\right]\left[4-\mathrm{O}(\mathrm{PEG})-\mathrm{C}_{6} \mathrm{H}_{4}\right]_{2}$ & 30200 & 30500 & 32400 & 1.20 & 75 \\
\hline$\left[(\mathrm{PFV})_{2}-3 \mathrm{~T}\right]\left(4-\mathrm{OSiMe}_{3}-\mathrm{C}_{6} \mathrm{H}_{4}\right)_{2}$ & 23300 & 18000 & 18200 & 1.16 & 78 \\
\hline$\left[(\mathrm{PFV})_{2}-3 \mathrm{~T}\right]\left(4-\mathrm{OH}-\mathrm{C}_{6} \mathrm{H}_{4}\right)_{2}$ & 22900 & 18100 & - & 1.29 & 70 \\
\hline$\left[(\mathrm{PFV})_{2}-3 \mathrm{~T}\right]\left[4-\mathrm{O}(\mathrm{PEG})-\mathrm{C}_{6} \mathrm{H}_{4}\right]_{2}$ & 22700 & 27100 & 28900 & 1.13 & 60 \\
\hline
\end{tabular}

${ }^{a}$ Synthetic conditions, see Scheme $7, \mathrm{PEG}(\mathrm{Ms})_{2}: M_{\mathrm{n}}=4600 ;{ }^{b} \mathrm{GPC}$ data in THF vs polystyrene standards;

${ }^{c}$ Calculated on the basis of molar ratio; ${ }^{d}$ Estimated by the integration ratio; ${ }^{e}$ Isolated yield.

\subsection{Precise One-Pot Synthesis of Fully Conjugated End-Functionalized Star Polymers}

On the basis of the above methodology, a facile, precise one-pot synthesis of end-functionalized star (triarm) polymers consisting of PFVs, the triblock copolymers (by incorporation of tri(2,5-dialkoxy1,4-phenylene vinylene) or terthiophene units as the middle segment), have been prepared by olefin metathesis followed by Wittig-type coupling. The key step of the synthesis is (i) olefin metathesis of 
the vinyl group in the PFV chain ends, (ii) treatment with core molecule [tris(4-formylphenyl)amine etc.], and (iii) reaction with various aldehyde (Scheme 9) [30].

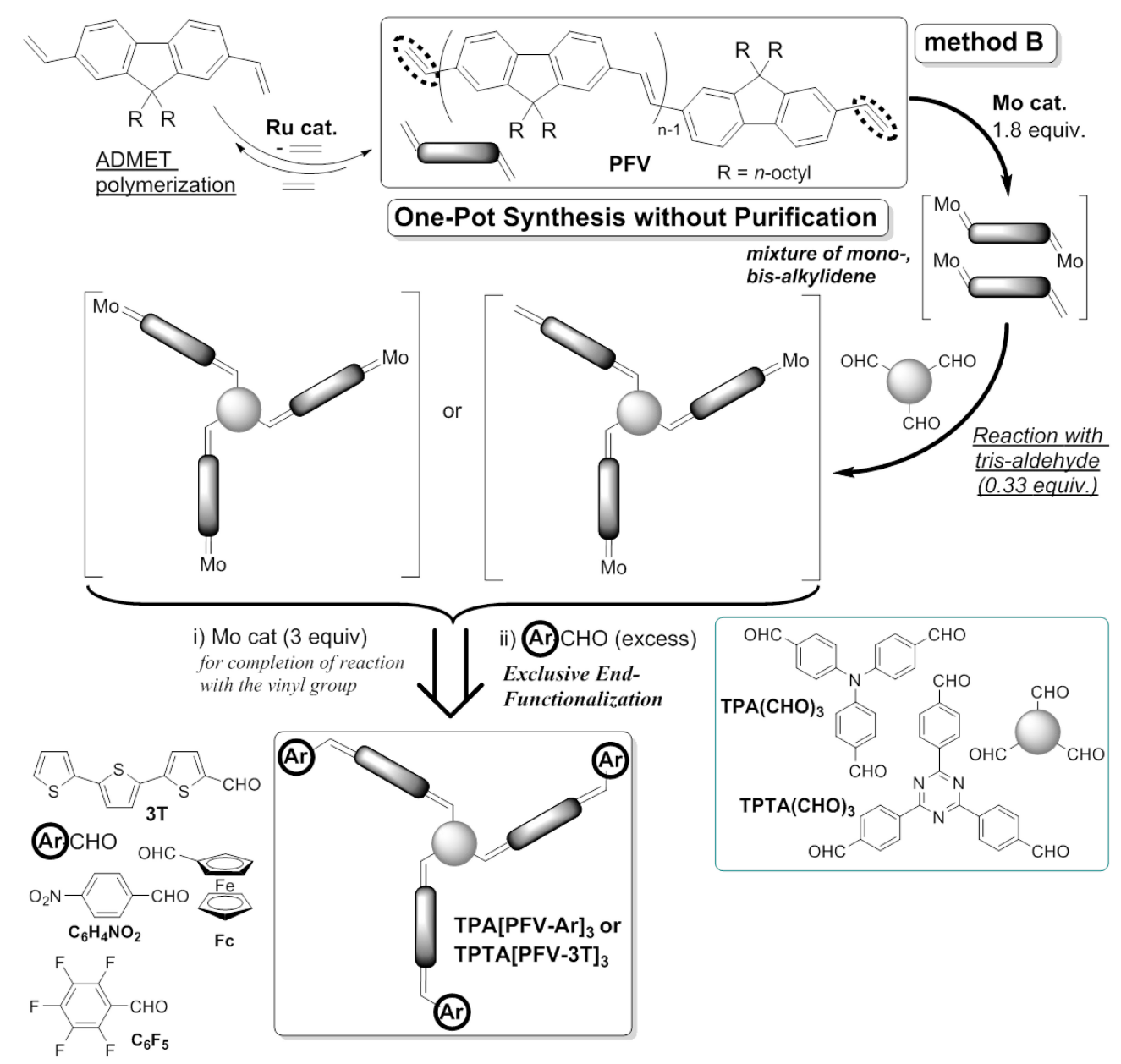

Scheme 9. Synthesis of end-functionalized triblock conjugated copolymers [30].

As shown in Scheme 9, the vinyl groups in the PFVs' chain ends were treated with Mo cat. (1.8 equiv to PFV), and the mixture was then added a $\mathrm{CH}_{2} \mathrm{Cl}_{2}$ solution containing $\mathbf{T P A}(\mathbf{C H O})_{3}$. The reaction solution was added a toluene solution containing Mo cat (3 equiv) for completion of the olefin metathesis (with the vinyl group in the PFV chain ends), and the subsequent addition of aldehyde (ArCHO) in excess amount afforded the end-functionalized star (triarm) copolymers, TPA[PFV-Ar $]_{3}$ (Ar $=\mathrm{C}_{6} \mathrm{~F}_{5}$, ferrocene $(\mathrm{Fc})$ ). The $M_{\mathrm{n}}$ values in TPA[PFV-Ar $]_{3}$, estimated by GPC, were analogous to the estimated values with unimodal molecular weight distributions. Resonances ascribed to protons of the vinyl groups in the starting PFVs were not observed in the ${ }^{1} \mathrm{H}$ NMR spectra, whereas resonances ascribed to protons in ferrocene moiety were clearly observed. Moreover, the estimated $M_{\mathrm{n}}$ values on the basis of integration in TPA[PFV-Fc $]_{3}$ were highly analogous to the calculated values on the basis of molar ratios, suggesting an exclusive formation of end-functionalized star conjugated polymers, TPA[PFV-Ar] $]_{3}$. The method can also be applied for synthesis of the star polymers containing triblock copolymers as the arm segment [30]. 


\section{Summary and Outlook}

The present account introduces the synthesis of conjugated polymers, poly(arylene vinylene)s, known as promising molecular electronics, by acyclic diene metathesis (ADMET) polymerization. The method is suitable to synthesis of high molecular weight, defect-free, stereo-regular (exclusive trans) polymers with well-defined chain ends. The chain ends (vinyl group) in the resultant polymer prepared by ruthenium-carbene catalyst(s) can be modified by treating with molybdenum-alkylidene complex (olefin metathesis) followed by addition of various aldehyde (Wittig type cleavage), affording the end-functionalized polymers exclusively. This is the very limited method for introduction of functionality into the chain ends of the conjugated polymers. An introduction of initiating fragment, the other conjugated segment, and one-pot synthesis of end-functionalized block copolymers as can be achieved by adopting this methodology, although the ADMET polymerization is a step growth polymerization and the precise control of molecular weight (like living polymerization) cannot be achieved. Since unique emission properties have been observed probably due to an energy transfer by introduction of oligo(thiophene)s [26], and chomophores [28] into the PFV chain ends, the method thus provides a new possibility for synthesis new type of advanced optical materials on the basis of integration of functionality. Although the present approaches require molybdenum-alkylidene catalyst (reagent) for the end-functionalization, the direct chain transfer pathway [36-38] may be considered in the future. We highly believe that the facts demonstrated here would offer a new possibility for development of new advanced materials/devises for the desired purpose.

\section{Acknowledgments}

The project is partly supported by Advanced Catalytic Transformation for Carbon utilization (ACT-C), Japan Science and Technology Agency (JST).

\section{Author Contributions}

This reviewing article was prepared by Tahmina Haque and Kotohiro Nomura. T.H. prepared the initial draft and K.N. finalized the text and drawings as the corresponding author.

\section{Conflicts of Interest}

The authors declare no conflict of interest.

\section{References}

1. Müllen, K. Organic Light Emitting Devices; Scherf, U., Ed.; Wiley-VCH: Winheim, Germany, 2006.

2. Skotheim, T.A. Handbook of Conducting Polymers, 3rd ed.; Reynolds, J., Ed.; CRC Press: Boca Raton, FL, USA, 2007.

3. Jenekhe, S.A., Ed.; Special Issue in Organic Electronics; American Chemical Society: Washington, DC, USA, 2004; Volume 16, pp. 4381-4842. 
4. Grimsdale, A.C.; Chan, K.L.; Martin, R.E.; Jokisz, P.G.; Holmes, A.B. Synthesis of light-emitting conjugated polymers for applications in electroluminescent devices. Chem. Rev. 2009, 109, 897-1091.

5. Burn, P.L.; Bradley, D.D.C.; Friend, R.H.; Halliday, D.A.; Holmes, A.B.; Jackson, R.W.; Kraft, A. Precursor route chemistry and electronic properties of poly( $p$-phenylenevinylene), poly[(2,5-dimethyl-p-phenylene)vinylene], and poly[(2,5-dimethoxy- $p$-phenylene)vinylene]. J. Chem. Soc. Perkins Trans. 1992, 1, 3225-3231.

6. Breemen, A.J.J.M.; Issaris, A.C.; de Kok, M.M.; van der Borght, M.J.A.N.; Adriaensens, P.J.; Gelan, J.M.J.V.; Vanderzande, D.J.M. Optimization of the polymerization process of sulfinyl precursor polymers toward poly(p-phenylene vinylene). Macromolecules 1999, 32, 5728-5735.

7. Lehman, S.E., Jr.; Wagener, K.B. ADMET polymerization. In Handbook of Metathesis; Grubbs, R.H., Ed.; Wiley-VCH: Weinheim, Germany, 2003; Volume 3, pp. 283-353.

8. Baughman, T.W.; Wagener, K.B. Recent advances in ADMET polymerization. In Advances in Polymer Science, Buchmeiser, M.R., Ed.; Springer: Heidelberg, Germany, 2005; Volume 176, pp. $1-42$.

9. Berda, E.B.; Wagener, K.B. Advances in acyclic diene metathesis polymerization. In Polymer Science: A Comprehensive Reference; Matyjaszewski, K., Müllen, M., Eds.; Elsevier BV: Amsterdam, Netherlands, 2012; Volume 5, pp. 195-216.

10. Berda, E.B.; Wagener, K.B. Recent advances in ADMET polycondensation chemistry. In Synthesis of Polymers; New Structures and Methods; Schluter, D., Hawker, C., Sakamosto, J., Eds.; Wiley-VCH: Weinhein, Germany, 2012; pp. 587-600.

11. Atallah, P.; Wagener, K.B.; Schulz, M.D. ADMET: The future revealed. Macromolecules 2013, 46, 4735-4741.

12. Thorn-Csányi, E.; Kraxner, P. Synthesis of soluble, all-trans poly(2,5-diheptyl- $p$ phenylenevinylene) via metathesis polycondensation. Macromol. Rapid Commun. 1995, 16, 147-153.

13. Thorn-Csányi, E.; Kraxner, P. Investigations of stable molybdenum carbene complexes for the metathesis synthesis of dialkylsubstituted poly(p-phenylenevinylene)s (PPVs). J. Mol. Catal. A 1997, 115, 21-28.

14. Thorn-Csányi, E.; Kraxner, P. All-trans oligomers of 2,5-dialkyl-1,4-phenylenevinylenesmetathesis preparation and characterization. Macromol. Chem. Phys. 1997, 198, 3827-3843.

15. Thorn-Csányi, E.; Kraxner, P. Synthesis of soluble all-trans oligomers of 2,5-diheptyloxy- $p$ phenylenevinylene via olefin metathesis. Macromol. Rapid Commun. 1998, 19, 223-228.

16. Schlick, H.; Stelzer, F.; Tasch, S.; Leising, G. Highly luminescent poly[( $m$-phenylenevinylene)co-( $p$-phenylenevinylene)] derivatives synthesized via metathesis condensation (ADMET). $J$. Mol. Catal. A 2000, 160, 71-84.

17. Thorn-Csányi, E.; Herzog, O. Synthesis of higher, trans configured oligomers of diisoalkyloxysubstituted divinylbenzenes (PV-oligomers) via metathesis telomerization of the corresponding lower oligomers. J. Mol. Catal. A 2004, 213, 123-128. 
18. Joo, S.-H.; Jin, J.-I. All hydrocarbon main-chain thermotropic liquid crystalline polymers, poly $\left(1,1^{\prime}\right.$-biphenylene-4,4'-alkenediyl)s, prepared by the ADMET method and their hydrogenated polymers, poly(1,1'-biphenylene-4,4'-alkanediyl)s. J. Polym. Sci., Part A 2004, 42, 1335-1349.

19. Oakley, G.W.; Wagener, K. Solid-state olefin metathesis: ADMET of rigid-rod polymers and ring-closing metathesis. Macromol. Chem. Phys. 2005, 206, 15-24.

20. Pecher, J.; Mecking, S. Nanoparticles from step-growth coordination polymerization. Macromolecules 2007, 40, 7733-7735.

21. Nomura, K.; Morimoto, H.; Imanishi, Y.; Ramhani, Z.; Geerts, Y. Synthesis of high molecular weight trans-poly(9,9-di- $n$-octylfluorene-2,7-vinylene) by the acyclic diene metathesis polymerization using molybdenum catalysts. J. Polym. Sci. Part A 2001, 39, 2463-2470.

22. Nomura, K.; Miyamoto, Y.; Morimoto, H.; Geerts, Y. Acyclic diene metathesis polymerization of 2,5-dialkyl-1,4-divinylbenzene with molybdenum or ruthenium catalysts: Factors affecting the precise synthesis of defect-free, high-molecular-weight trans-poly(p-phenylene vinylene)s. J. Polym. Sci., Part A: Poly. Chem. 2005, 43, 6166-6177.

23. Yamamoto, N.; Ito, R.; Geerts, Y.; Nomura, K. Synthesis of all-trans high molecular weight poly( $N$-alkylcarbazole-2,7-vinylene)s and poly(9,9-dialkylfluorene-2,7-vinylene)s by acyclic diene metathesis (ADMET) polymerization using ruthenium-carbene complex catalysts. Macromolecules 2009, 42, 5104-5111.

24. Weychardt, H.; Plenio, H. Acyclic diene metathesis polymerization of divinylarenes and divinylferrocenes with Grubbs-type olefin metathesis catalysts. Organometallics 2008, 27, 1479-1485.

25. Nomura, K.; Yamamoto, N.; Ito, R.; Fujiki, M.; Geerts, Y. Exclusive end functionalization of all-trans-poly(fluorene vinylene)s prepared by acyclic diene metathesis polymerization: facile efficient synthesis of amphiphilic triblock copolymers by grafting poly(ethylene glycol). Macromolecules 2008, 41, 4245-4249.

26. Kuwabara, S.; Yamamoto, N.; Sharma, P.M.V.; Takamizu, K.; Fujiki, M.; Geerts, Y.; Nomura, K. Precise synthesis of poly(fluorene-2,7-vinylene)s containing oligo(thiophene)s at the chain ends: unique emission properties by the end functionalization. Macromolecules 2011, 44, 3705-3711.

27. Abdellatif, M.M.; Nomura, K. Precise synthesis of amphiphilic multiblock copolymers by combination of acyclic diene metathesis (ADMET) polymerization with atom transfer radical polymerization (ATRP) and click chemistry. ACS Macro Lett. 2012, 1, 423-427.

28. Takamizu, K.; Inagaki, A.; Nomura, K. Precise synthesis of poly(fluorene vinylene)s capped with chromophores: Efficient fluorescent polymers modified by conjugation length and end-groups. ACS Macro Lett. 2013, 2, 980-984.

29. Nomura, K.; Haque, T.; Onuma, T.; Hajjaj, F.; Asano, M.S.; Inagaki, A. Precise one-pot synthesis of end-functionalized conjugated multi-block copolymers via combined olefin metathesis and Wittig-type coupling. Macromolecules 2013, 46, 9563-9574.

30. Nomura, K.; Haque, T.; Miwata, T.; Inagaki, A.; Takamizu, K. Precise one-oot synthesis of fully conjugated end functionalized starpolymers containing poly(fluorene-2,7-vinylene) (PFV) arms. Polymer Chem. 2015, 6, 380-388.

31. Anuragudom, P.; Newaz, S.S.; Phanichphant, S.; Lee, T.R. Facile Horner-Emmons synthesis of defect-free poly(9,9-dialkylfluorenyl-2,7-vinylene). Macromolecules 2006, 39, 3494-3499. 
32. Liu, Q.; Liu, W.; Yao, B.; Tian, H.; Xie, Z.; Geng, Y.; Wang, F. Synthesis and chain-length dependent properties of monodisperse oligo(9,9-di-n-octylfluorene-2,7-vinylene)s. Macromolecules 2007, 40, 1851-1857.

33. Nomura, K.; Abdellatif, M.M. Precise synthesis of polymers containing functional end groups by living ring-opening metathesis polymerization (ROMP): Efficient tools for synthesis of block/graft copolymers. Polymer 2010, 51, 1861-1881.

34. Abdellatif, M.M.; Nomura, K. Precise synthesis of end-functionalized oligo(2,5-dialkoxy-1,4phenylene vinylene)s with controlled repeat units via combined olefin metathesis and Wittig-type coupling. Org. Lett. 2013, 15, 1618-1621.

35. Abdellatif, M.M.; Yorsaeng, S.; Inagaki, A.; Nomura, K. Synthesis of end functionalized oligo(2,5-dialkoxy-1,4-phenylene vinylene)s. Macromol. Chem. Phys. 2014, 215, 1973-1983.

36. Hillmyer, M.A.; Nguyen, S.B.T.; Grubbs, R.H. Utility of a ruthenium metathesis catalyst for the preparation of end-functionalized polybutadiene. Macromolecules 1997, 30, 718-721.

37. Pitet, L.M.; Hillmyer, M.A. Carboxy-telechelic polyolefins by ROMP using maleic acid as a chain transfer agent. Macromolecules 2011, 44, 2378-2381.

38. Lin, T.-W.; Chou, C.-M.; Lin, N.-T.; Lin, C.-L.; Luh, T.-Y. End group modification of polynorbornenes Macromol. Chem. Phys. 2014, 215, 2357-2364.

(C) 2015 by the authors; licensee MDPI, Basel, Switzerland. This article is an open access article distributed under the terms and conditions of the Creative Commons Attribution license (http://creativecommons.org/licenses/by/4.0/). 